\title{
Prevalence of microalbuminuria, lipoprotein (a) and coronary artery disease in the lipid clinic
}

Department of Medicine, UMDS, St Thomas's Hospital, London

M H Cummings

A Tavakolian

Department of Public Heath Medicine

A Fitzgerald

University

Department of

Medicine, The

University of Western

Australia, Perth,

Western Australia

G F Watts

Correspondence to: Dr M Cummings,

Department of Medicine,

North Wing, St Thomas's

Horth

Road, London SE1 7EH.

Accepted for publication

11 September 1995

\begin{abstract}
Aims-To assess the prevalence of microalbuminuria (MA) and elevated serum lipoprotein (a) ( $\mathbf{L p}(\mathrm{a})$ ) concentration, and their association with coronary artery disease (CAD) and other conventional cardiovascular risk factors in non-diabetic patients attending a lipid clinic.
\end{abstract}

Methods-Clinical details were obtained from 96 consecutive non-diabetic patients from whom a fasting blood sample was taken to measure serum lipid, lipoprotein, apolipoprotein and plasma glucose, urea, and electrolyte concentrations. The urine albumin/creatinine ratio $\left(U_{a} / U_{c}\right)$ was estimated from a random clinic sample.

Results-Of the patients, $26 \%$ had MA (defined as a $\left.U_{a} / U_{c}>2 \cdot 2 \mathrm{mg} / \mu \mathrm{mol}\right), 38 \%$ had an elevated $L_{p}$ (a) concentration (defined as $>0.4 \mathrm{~g} / \mathrm{l}$ ), $36 \%$ were hypertensive (blood pressure $>160 / 95$ ) or were taking antihypertensive medication, and $25 \%$ had established CAD defined on clinical criteria. In men the $U_{a} / U_{c}$ ratio was highly associated with age, plasma low density lipoprotein cholesterol, and triglyceride concentrations. In women there was no association between the $U_{a} / U_{c}$ ratio and variables examined. $L p$ (a) concentration was not associated with variables examined in either sex. In multiple logistic regression analysis adjusted for age and sex, serum Lp (a) concentration, diastolic blood pressure and treatment of hyperlipidaemia were highly associated with CAD. MA was not, however, associated with CAD.

Conclusions-MA is common in a lipid clinic and is more likely to be found among older male patients with hyperlipidaemia. However, in contrast with $L p$ (a) concentrations, MA is not a risk factor for CAD in this high risk population. Lp (a) concentration may be a useful tool in the lipid clinic, but there does not seem to be a justification for measuring the $U_{a} / U_{c}$ ratio, at least in non-diabetic subjects. (f Clin Pathol 1996;49:19-23)

Keywords: microalbuminuria, lipoprotein (a), coronary artery disease, hyperlipidaemia.

Hyperlipidaemia is a well recognised risk factor for coronary artery disease (CAD). ${ }^{12}$ As an elevated cholesterol concentration is a common finding, ${ }^{3}$ treatment of hyperlipidaemic patients should aim to optimise available resources by targeting those with the worst cardiovascular prognosis. Over the past decade, the number of lipid clinics has expanded owing to increased awareness of the consequences of hyperlipidaemia and advances in treatment. The identification of high risk patients within this hyperlipidaemic population may potentially be enhanced by screening for additional cardiovascular risk factors such as microalbuminuria ${ }^{4}$ and raised lipoprotein (a) (Lp (a)) concentration. ${ }^{5}$ Hitherto, however, the prevalence and associations of microalbuminuria and elevated $\mathrm{Lp}$ (a) concentration in patients attending a lipid clinic have not been examined.

Several studies have established that in diabetes mellitus microalbuminuria not only predicts the development of nephropathy, ${ }^{6}$ but also of CAD. ${ }^{7-9}$ Some studies have also suggested that microalbuminuria is associated with $\mathrm{CAD}$ in the non-diabetic population. ${ }^{10-12}$ The mechanism linking CAD to microalbuminuria is not fully established and it is possible that microalbuminuria represents a nexus for expression of other cardiovascular risk factors such as hyperlipidaemia and impaired glucose intolerance. ${ }^{1113-15}$ Microalbuminuria may also be a marker of vascular dysfunction, reflecting the susceptibility of arterial endothelium to risk factor mediated damage. ${ }^{4}$ It may therefore be expected that microalbuminuria will be highly prevalent and independently predictive of CAD in patients attending a lipid clinic.

Another potential risk factor for atherosclerosis is Lp (a), several studies having shown an association between serum Lp (a) concentration and CAD. ${ }^{16-18}$ It has been suggested, however, that increased cardiovascular risk associated with $\mathrm{Lp}$ (a) may only occur in patients with a high plasma low density lipoprotein (LDL) cholesterol concentration. ${ }^{5}$ This observation has been based mainly on the study of patients with familial hypercholesterolaemia ${ }^{17}$ but an elevated $\mathrm{Lp}$ (a) concentration may also confer additional cardiovascular risk in more common hyperlipidaemias. ${ }^{19}$ Elevated serum $\mathrm{Lp}$ (a) concentration has also been associated with microalbuminuria. ${ }^{2021}$

Our study examined patients attending a lipid clinic to determine the prevalence and clinical associations of microalbuminuria and elevated serum $\mathrm{Lp}$ (a) concentration. We were also specifically interested in whether these measurements were independent correlates of the presence of CAD in this high risk population.

\section{Methods}

Consecutive patients $(n=106)$ attending the lipid clinic at St Thomas's Hospital were 
Table 1 Clinical and biochemical features of the patients studied

\begin{tabular}{|c|c|c|}
\hline Variable & $\begin{array}{l}\text { Men }(n=53) \\
\text { Mean }(S D)\end{array}$ & $\begin{array}{l}\text { Women }(n=43) \\
\text { Mean }(S D)\end{array}$ \\
\hline Age (years) & $48 \cdot 3 \quad(12 \cdot 3)$ & $58 \cdot 1 \quad(11 \cdot 3)$ \\
\hline Weight (kg) & $77.5 \quad(11.0)$ & $68.0 \quad(12.9)$ \\
\hline Height $(\mathrm{cm})$ & $173.0 \quad(5 \cdot 5)$ & $161 \cdot 8 \quad(6 \cdot 1)$ \\
\hline BMI $\left(\mathrm{kg} / \mathrm{m}^{2}\right)$ & $26 \cdot 1 \quad(0 \cdot 4)$ & $26 \cdot 7 \quad(0.5)$ \\
\hline Systolic BP (mmHg) & $132 \cdot 2 \quad(20 \cdot 6)$ & $140 \cdot 1 \quad(21 \cdot 6)$ \\
\hline Diastolic BP (mmHg) & $82 \cdot 8 \quad(11 \cdot 3)$ & $86 \cdot 7 \quad(9 \cdot 2)$ \\
\hline $\mathrm{U}_{\mathrm{a}} / \mathrm{U}_{\mathrm{c}}(\mathrm{mg} / \mu \mathrm{mol})^{*}$ & $1 \cdot 14(0 \cdot 26,4 \cdot 89)$ & $1 \cdot 81(0 \cdot 26,12 \cdot 80)$ \\
\hline $\mathrm{TC}(\mathrm{mmol} / \mathrm{l})$ & $6 \cdot 85(1 \cdot 15)$ & $7.51(1.33)$ \\
\hline $\mathrm{TG}(\mathrm{mmol} / \mathrm{l})^{*}$ & $2 \cdot 58(0.67,9 \cdot 94)$ & $1.99(0.71,5 \cdot 60)$ \\
\hline HDL cholesterol $(\mathrm{mmol} / \mathrm{l})$ & $1 \cdot 1 \quad(0 \cdot 3)$ & $1.4 \quad(0.4)$ \\
\hline LDL cholesterol $(\mathrm{mmol} / \mathrm{l})$ & $4 \cdot 7 \quad(1 \cdot 2)$ & $5 \cdot 3 \quad(1.4)$ \\
\hline ApoAl $(g / 1)$ & $1.9 \quad(0 \cdot 3)$ & $2 \cdot 1 \quad(0 \cdot 3)$ \\
\hline ApoB $(g / 1)$ & $1.6 \quad(0.4)$ & $1.7 \quad(0.4)$ \\
\hline $\operatorname{Lp}(a)(g / l)^{*}$ & $0 \cdot 29(0 \cdot 06,1 \cdot 40)$ & $0.34(0.06,1.99)$ \\
\hline Glucose $(\mathrm{mmol} / \mathrm{l})$ & $5 \cdot 1 \quad(0 \cdot 5)$ & $5 \cdot 1(0 \cdot 7)$ \\
\hline
\end{tabular}

$\mathrm{BMI}=$ body mass index; $\mathrm{BP}=$ blood pressure; * geometric mean (95\% range).

screened for microalbuminuria. Clinical details were recorded to identify patients with hypertension, macrovascular disease (CAD, peripheral vascular disease or cerebrovascular disease) or diabetes mellitus. Current drug therapy, smoking habits and family history of macrovascular disease were also recorded. Each patient was venesected following a 12 hour fast to determine serum total cholesterol (TC), triglyceride (TG), high density lipoprotein (HDL) cholesterol, apolipoprotein A1 (apoA1), apolipoprotein B (apoB), Lp (a), and plasma glucose, urea and electrolyte concentrations. Ten patients were excluded from the study because of diabetes mellitus (defined by the WHO criteria), macroproteinuria, or raised plasma creatinine concentration $(>150$ $\mu \mathrm{mol} / 1)$. This study received ethics committee approval.

\section{ANALYTICAL MEASUREMENTS}

A urine albumin/creatinine ratio $\left(\mathrm{U}_{\mathrm{a}} / \mathrm{U}_{\mathrm{c}}\right)$ was determined from analysis of a random urine sample. ${ }^{10}$ Urine samples were assayed within five days of collection, having been stored at $4^{\circ} \mathrm{C}$ prior to analysis. Urine albumin concentration (mg/l) was measured by immunoturbidimetry (Cobas Fara autoanalyser, Roche, Welwyn Garden City, Herts, UK), interassay coefficient of variation $(\mathrm{CV})<3 \cdot 7 \%$. Urine creatinine concentration $(\mu \mathrm{mol} / \mathrm{l})$ was estimated by a modified, end point Jaffé reaction using a Cobas Bio autoanalyser (Roche), CV $2 \cdot 8 \%$. HDL cholesterol, plasma TC and TG concentrations ( $\mathrm{mmol} / \mathrm{l})$ were measured by an enzymatic method (Boehringer Mannheim,

Table 2 The prevalence of microalbuminuria, raised $L p$ (a) concentration, dyslipidaemia, hypertension, smokers, drug treatment for hypertension and hyperlipidaemia, and macrovascular disease amongst the patients studied

\begin{tabular}{lll}
\hline Variable & $\begin{array}{l}\text { Men }(n=53) \\
\%(n)\end{array}$ & $\begin{array}{l}\text { Women }(n=43) \\
\%(n)\end{array}$ \\
\hline Hypertension & $28(15)$ & $47(20)$ \\
Hypercholesterolaemia & $94(50)$ & $98(42)$ \\
Hypertriglyceridaemia & $40(21)$ & $37(16)$ \\
Mixed hyperlipidaemia & $38(20)$ & $35(15)$ \\
Elevated Lp (a) concentration & $36(19)$ & $40(17)$ \\
Microalbuminuria & $19(10)$ & $35(15)$ \\
CAD & $32(17)$ & $16(7)$ \\
Peripheral vascular disease & $9(5)$ & $9(4)$ \\
Cerebrovascular disease & $8(4)$ & $65(28)$ \\
Family history of macrovascular disease & $42(22)$ & $12(5)$ \\
Smokers & $19(10)$ & $35(15)$ \\
Drug treatment for hypertension & $23(12)$ & $67(29)$ \\
Drug treatment for hyperlipidaemia & $72(38)$ & \\
\hline
\end{tabular}

Sussex, UK) using a Cobas centrifugal analyser (Roche). HDL was separated by precipitation of apoB containing lipoproteins with dextran sulphate/magnesium chloride. LDL cholesterol concentration $(\mathrm{mmol} / \mathrm{l})$ was estimated using the Friedewald equation in patients with TG concentrations $<4.5 \mathrm{mmol} / \mathrm{l}$. In patients with TG $>4.5 \mathrm{mmol} / 1$, cholesterol concentration was measured directly in LDL following preparative ultracentrifugation. ApoA1, apoB and Lp (a) concentrations $(\mathrm{g} / \mathrm{l})$ were measured by immunoturbidimetry (Cobas Fara autoanalyser, Roche) using commercially available kits (Immunoturb kit, Immuno, Sevenoaks, UK), CV $<2 \cdot 8 \%, 2 \cdot 7 \%$ and $2 \cdot 4 \%$ respectively. ${ }^{22}$ Plasma glucose $(\mathrm{mmol} / \mathrm{l})$ was measured by a glucose oxidase technique (DAX 96, Bayer Diagnostics, Basingstoke, UK), CV 3\%.

\section{DEFINITIONS}

CAD was defined according to a history of myocardial infarction, coronary artery bypass surgery or the use of anti-anginal medication, ${ }^{23}$ or ECG abnormalities at rest or on exercise compatible with CAD. ${ }^{24}$ Hypertension was defined as a systolic pressure of $>160 \mathrm{mmHg}$ and/or a diastolic pressure $>95 \mathrm{mmHg}$ (WHO criteria) and/or a history of hypertension requiring treatment. ${ }^{25}$ Microalbuminuria was defined as a $\mathrm{U}_{\mathrm{a}} / \mathrm{U}_{\mathrm{c}}$ ratio $>2 \cdot 2 \mathrm{mg} / \mu \mathrm{mol}$ (equivalent to an albumin excretion rate $>15 \mathrm{~g} / \mathrm{min})^{26}$ in the absence of macroalbuminuria (Albustix negative). Hyperlipidaemia was defined as total cholesterol concentration $>5 \cdot 2 \mathrm{mmol} / \mathrm{l}$, and/or LDL cholesterol $>3.5 \mathrm{mmol} / \mathrm{l}$, and/or triglyceride concentration $>2.5 \mathrm{mmol} / 1 .^{2} \mathrm{Lp}$ (a) concentration was considered raised if above $0 \cdot 4 \mathrm{~g} / 1 .{ }^{17}$

\section{STATISTICAL ANALYSES}

Data were analysed using the SAS statistical package (SAS Institute Inc., Cary, North Carolina, USA). Normally distributed data were expressed as mean (SD). Skewed variables (plasma TG and Lp (a) concentrations and $\mathrm{U}_{\mathrm{a}} / \mathrm{U}_{\mathrm{c}}$ ratio) were expressed as geometric mean ( $95 \%$ range). Associations between the $U_{a} / U_{c}$ ratio, $\mathrm{Lp}$ (a) concentration and other variables were examined using Spearman's rank correlation. To determine associates of $\mathrm{CAD}$, univariate associations were examined using logistic analysis adjusted for age and sex. Skewed variables were examined after logarithmic transformation. Stepwise multiple logistic regression analysis, also adjusted for age and sex, was used to assess the relative strength of association with CAD; significance levels for entry and exit were set at $0 \cdot 10$. For continuous risk factors, the standardised relative odds, which indicates the relative change in risk associated with an increase of one standard deviation, is quoted.

\section{Results}

The clinical and biochemical features of the patients studied are shown in table 1 . Women were older and had higher TC, HDL cho- 
Table 3 Association between CAD and variables assessed by univariate logistic analysis, adjusted for age and sex

\begin{tabular}{|c|c|c|c|c|}
\hline Risk factor & $\begin{array}{l}\text { Odds ratio* (95\% } \\
\text { confidence interval) }\end{array}$ & $\begin{array}{l}\text { Regression } \\
\text { coefficient }\end{array}$ & $\begin{array}{l}\text { Standard } \\
\text { error }\end{array}$ & $p$ value \\
\hline $\begin{array}{l}\text { Total cholesterol } \\
\text { Systolic BP } \\
\text { Diastolic BP } \\
\text { Lp (a) } \\
\text { Drug treatment for hyperlipidaemia† }\end{array}$ & $\begin{array}{l}0.54(0.28,1.03) \\
0.46(0.24,0.85) \\
0.38(0.20,0.74) \\
2 \cdot 68(1.41,5 \cdot 08) \\
4.55(1.35,27 \cdot 51)\end{array}$ & $\begin{array}{r}-0.49 \\
-0.04 \\
-0.09 \\
1.17 \\
1.52\end{array}$ & $\begin{array}{l}0 \cdot 26 \\
0 \cdot 01 \\
0 \cdot 03 \\
0 \cdot 39 \\
0 \cdot 54\end{array}$ & $\begin{array}{l}0.06 \\
0.01 \\
0.004 \\
0.003 \\
0.02\end{array}$ \\
\hline
\end{tabular}

* Odds ratio associated with an increase of 1 standard deviation.

† Odds ratio associated with taking lipid lowering medication. $\mathrm{BP}=$ blood pressure.

Table 4 Association between CAD and variables assessed by stepwise logistic regression analysis, adjusted for age and sex

\begin{tabular}{lcccc}
\hline Risk factor & $\begin{array}{l}\text { Odds ratio* }(95 \% \\
\text { confidence interval) }\end{array}$ & $\begin{array}{l}\text { Regression } \\
\text { coefficient }\end{array}$ & $\begin{array}{l}\text { Standard } \\
\text { error }\end{array}$ & $p$ value \\
\hline $\begin{array}{l}\text { Lp (a) } \\
\begin{array}{l}\text { Drug treatment for } \\
\text { hyperlipidaemiat }\end{array}\end{array}$ & $2.91(1.38,6.13)$ & 1.26 & 0.45 & 0.005 \\
$\begin{array}{l}\text { Diastolic BP } \\
\text { P }\end{array}$ & $11.63(1.52,88.89)$ & 2.45 & 1.04 & 0.02 \\
\hline
\end{tabular}

* Odds ratio associated with an increase of 1 standard deviation.

† Odds ratio associated with taking lipid lowering medication. $\mathrm{BP}=$ blood pressure.

lesterol and Lp (a) concentrations compared with the men. The overall prevalences of microalbuminuria, elevated Lp (a) concentration, hypertension, and $\mathrm{CAD}$ were $26 \%, 38 \%, 36 \%$, and $25 \%$, respectively (table 2). Although $36 \%$ of this population were defined as hypertensive, only $74 \%$ of these patients were being treated with anti-hypertensive medication. There was a higher prevalence of hypertension, microalbuminuria and family history of macrovascular disease in women compared with men but fewer women smoked and their prevalence of $\mathrm{CAD}$ was lower $(16 \% v 32 \%)$. In men there were significant associations between the $\mathrm{U}_{\mathrm{a}} /$ $\mathrm{U}_{\mathrm{c}}$ ratio and age, plasma LDL cholesterol, and TG concentrations $(r=0.30, p=0.02 ; r=$ $-0.28, \mathrm{p}=0.04$; and $\mathrm{r}=0.31, \mathrm{p}=0.03$, respectively). In women no associations were noted between the $U_{a} / U_{c}$ ratio and the variables examined. Lp (a) concentration was not associated with variables examined in either sex. In addition, there was no significant difference in these variables when comparing patients with elevated and normal Lp (a) concentrations.

Univariate logistic analysis showed that $\mathrm{Lp}$ (a) concentration and treatment of hyperlipidaemia were significantly, positively associated with $\mathrm{CAD}$ (table 3 ). In this population, however, risk of CAD was significantly, inversely associated with TC concentration, and systolic and diastolic blood pressure. Neither the $U_{a} / U_{c}$ ratio nor microalbuminuria were significantly associated with CAD $(\mathrm{p}=0.21$ and $\mathrm{p}=0.71$, respectively). Multiple logistic regression analysis demonstrated that $\mathrm{Lp}$ (a) concentration, diastolic blood pressure and drug treatment for hyperlipidaemia were the factors most strongly associated with CAD (table 4).

\section{Discussion}

This is the first study to examine the prevalence and associations of microalbuminuria and elevated $\mathrm{Lp}$ (a) concentration in non-diabetic patients attending a lipid clinic. In this crosssectional study of patients with a clustering of risk factors for $C A D$, we have shown that microalbuminuria was highly prevalent, but was not associated with CAD. Elevated Lp (a) concentration was also highly prevalent, being present in over one third of the patients but, in contrast to microalbuminuria, was significantly associated with CAD.

The prevalence of microalbuminuria in the present study was higher than in non-diabetic populations reported previously. ${ }^{10112728}$ In addition, our findings differ from studies of nondiabetic subjects randomly selected from the community, where microalbuminuria was found to be associated with CAD. ${ }^{10-12}$ It is likely that this disparity in findings between the present and other studies is due mainly to differences in patient characteristics. In our study, there was a higher prevalence of hypertension compared with other unselected, non-diabetic populations ${ }^{1011}$ and this risk factor for $\mathrm{CAD}$ is independently associated with microalbuminuria in diabetic ${ }^{7-9}$ and non-diabetic $^{10-12}$ subjects. In addition, there was selection bias as our patients were referred to a clinic because of established or high risk of CAD because of dyslipidaemia and other cardiovascular risk factors. The contrasting findings may also be due to different techniques used to measure urine albumin concentration or the different thresholds used to define microalbuminuria.

Several studies have shown an association between Lp (a) concentration, myocardial infarction $^{1617}$ or the extent of CAD assessed angiographically. ${ }^{18}$ However, whether Lp (a) is an independent risk factor for CAD, or is atherogenic only in the presence of raised LDL cholesterol remains unclear. ${ }^{5}$ The suggestion that cardiovascular risk from elevated $\mathrm{Lp}$ (a) concentration is greatest when LDL cholesterol concentration is raised, is derived predominantly from studies of familial hypercholesterolaemia ${ }^{17}$ although this may apply to other hyperlipidaemic conditions. ${ }^{19}$ Our study examined a heterogenous group of hyperlipidaemic patients and provides further evidence that $\mathrm{Lp}$ (a) concentration is an independent risk factor for CAD. Although two thirds of the patients studied were taking cholesterol lowering medication, none of these 
drugs have been consistently shown to lower serum $\mathrm{Lp}$ (a) concentration. ${ }^{5}$

Lp (a) possesses both thrombogenic and atherogenic properties which may mediate the increased cardiovascular risk associated with this lipoprotein. Given the sequence homology of apo (a) with plasminogen, ${ }^{29} \mathrm{Lp}$ (a) reduces fibrinolysis by inhibiting the binding of plasminogen to its receptor site. ${ }^{30} \mathrm{Lp}$ (a) is also found in high concentrations within atherosclerotic plaques $^{31}$ and it has been proposed that oxidation of the lipid component of $\mathrm{Lp}$ (a) could result in foam cell development, as seen with oxidised LDL. ${ }^{5}$ In other studies where microalbuminuria was associated with $\mathrm{CAD}$, the mechanism linking these two variables has not been fully established. Possible mediators of atherogenesis include disorders of lipid metabolism ${ }^{1113-15}$ and vascular endothelial dysfunction $^{32}$ which may be related to changes in the quality of the endothelial extracellular matrix. ${ }^{4}$

One possible shortcoming of our study is the definition of microalbuminuria based on the measurement of an $\mathrm{U}_{\mathrm{a}} / \mathrm{U}_{\mathrm{c}}$ ratio in a single random urine sample, as used by others. ${ }^{10} \mathrm{It}$ has been shown, however, that the $\mathrm{U}_{\mathrm{a}} / \mathrm{U}_{\mathrm{c}}$ ratio estimated from a single random urine sample correlates closely with albumin excretion rate in a 24 hour or overnight sample,,$^{33}$ and in noninsulin dependent diabetic patients is of value in identifying patients with an increased risk of mortality or progression to nephropathy.$^{34}$ It is also possible that error occurred in measurement of $\mathrm{Lp}$ (a) concentration as analysis by immunoturbidimetry has been criticised for having low specificity for larger apo (a) isoforms. ${ }^{35}$ More recently, we have demonstrated that estimation of $\mathrm{Lp}$ (a) concentration by immunoturbidimetry using a highly specific polyclonal antibody is highly correlated with a slight positive bias, when compared with measurement of Lp (a) by a standard enzyme linked immunosorbent assay method. ${ }^{19} \mathrm{We}$ also acknowledge that diagnosis of CAD based upon clinical and electrocardiographic evidence is relatively insensitive and that angiographic correlations may have proved more informative; evidence from previous studies ${ }^{18}$ suggests that these measurements would improve the statistical significance of the correlation with $\mathrm{Lp}$ (a) concentration.

Some caution is required in interpreting results from our cross-sectional study of a highly selected population. This high risk population was studied for practical reasons as patients attending a lipid clinic are likely to have a great impact on available hospital resources. The absence of significant association between microalbuminuria and CAD in our hyperlipidaemic population may be due to overrepresentation of conventional cardiovascular risk factors such as dyslipidaemia, smoking and hypertension. The association between conventional risk factors and $\mathrm{CAD}$ is difficult to assess in the present population, however, as our patients were already receiving treatment aimed at reducing cardiovascular risk. This would explain why an increased risk of CAD was associated with lower cholesterol con- centration and blood pressure; patients who were initially hypertensive, hypercholesterolaemic, who presented with established $\mathrm{CAD}$, or were at high risk of atherosclerosis, were more likely to receive aggressive lipid lowering or anti-hypertensive treatment.

In conclusion, elevated $\mathrm{Lp}$ (a) concentration, but not microalbuminuria, was associated with $\mathrm{CAD}$ in patients attending a lipid clinic. We suggest that measurement of $\mathrm{Lp}$ (a) concentration, but not the $U_{a} / U_{c}$ ratio, may be useful in assessing and targeting treatment in this high risk population. In order to confirm our findings, however, longitudinal studies examining the relation among the $\mathrm{U}_{\mathrm{a}} / \mathrm{U}_{\mathrm{c}}$ ratio, $\mathrm{Lp}$ (a) concentration and the development of $\mathrm{CAD}$ are required. Moreover, interventional studies are needed to determine whether decreasing $\mathrm{Lp}$ (a) concentration reduces the risk of CAD. As there are currently no potent $\mathrm{Lp}$ (a) lowering agents available, more aggressive intervention of other treatable cardiovascular risk factors may be warranted.

We thank Mr Peter Lumb and the staff of the Department of Chemical Pathology, St Thomas's Hospital, for carrying out the biochemical analyses.

1 Study Group, European Atherosclerosis Society. Strategies for the prevention of coronary heart disease: a policy statement from the European Atherosclerosis Society. Eur Heart f 1987;8:77-88.

2 Betteridge DJ, Dodson PM, Durrington PN, Hughs EA, Laker MF, Nicolls DP, et al. Management of hyperlipidaemia: guidelines of the British Hyperlipidaemia Association. Postgrad Med $\mathcal{f}$ 1993;69:359-69.

3 Mann JL, Lewis B, Shepherd J, Winder AF, Fenster S, Rose $\mathrm{L}$, et al. Blood lipid concentrations and other cardiovascular risk factors: distribution, prevalence and detection in Britain. $B M \mathcal{F}$ 1988;296:1702-6.

4 Deckert T, Koefoed-Enevoldsen A, Norgaard K, BorchJohnsen, Feldt-Ramussen B, Jensen T. Microalbuminuria. Implications for micro- and macrovascular disease. Diabetes Care 1992;15:1181-91.

5 MBewu AD, Durrington PN. Lipoprotein (a): structure, properties and possible involvement in thrombogenesis and atherogenesis. Atherosclerosis 1990;85:1-14.

6 Mogensen CE, Christensen CK. Predicting diabetic nephropathy in insulin dependent patients. $N$ Engl $f \mathrm{Med}$ 1984;311:89-93.

7 Schmitz A, Vaeth M. Microalbuminuria: A major risk factor in non-insulin-dependent diabetes. A 10-year follow-up study of 503 patients. Diabet Med 1988;5:126-34.

8 Jarrett RJ, Viberti GC, Argyropoulos A, Hill RD, Mahmud U, Murrells TJ. Microalbuminuria predicts mortality in non-insulin-dependent diabetes. Diabet Med 1984;1:1719.

9 Mogensen CE. Microalbuminuria predicts clinical proteinuria and early mortality in maturity-onset diabetes. $N$ Engl $\mathcal{F}$ Med 1984;310:356-60.

10 Yudkin JS, Forrest RD, Jackson CA. Microalbuminuria: a predictor of vascular disease in non-diabetic subjects. Lancet 1988;208:530-3.

11 Winocour PH, Harland JOE, Millar JP, Laker MF, Alberti KGMM. Microalbuminuria and associated cardiovascular risk factors in the community. Atherosclerosis 1992;93: $71-81$.

12 Damsgaard EM, Froland A, Jorgensen OD, Mogensen CE. Microalbuminuria as predictor of increased mortality in elderly people. $B M \mp$ 1990;300:297.

13 Dullart RPF, Dikkeschei LD, Doorenbos H. Alterations in serum lipids and apolipoproteins in male type 1 (insulin dependent) diabetic patients with microalbuminuria. dependent) diabetic patients
Diabetologia 1989;32:685-9.

14 Watts GF, Naoumova R, Slavin BM, Morris RW, Houlston $\mathrm{R}$, Kubal $\mathrm{C}$, et al. Serum lipids and lipoproteins in insulindependent diabetic patients with persistent microdependent diabetic patients with pers
albuminuria. Diabetic Med 1989;6:25-30.

15 Niskanen L, Uusitupa M, Sarlund H, Siitonen O, VouNiskanen L, Uusitupa M, Sarlund H, Siitonen O, Vou-
tilainen E, Penttila I, et al. Microalbuminuria predicts the development of serum lipoprotein abnormalities favouring atherogenesis in newly diagnosed type 2 (non-insulindependent) diabetic patients. Diabetologia 1990;33:23743.

16 Rhoads GG, Dahlen G, Berg K, Morton NE, Dannenberg Al. Lp (a) as a risk factor for myocardial infarction. $\mathcal{f} A M A$ 1986;256:2540-4.

17 Seed M, Hoppichler F, Reaveley D, McCarthy S, Thompson GR, Boerwinkle E, et al. Relation of serum lipoprotein (a) concentration and apolipoprotein (a) phenotype to coronary heart disease in patients with familial hypercholesterolaemia. $N$ Engl f Med 1990;322:1494-9. 
18 Dahlen GH, Guyton JT, Attar M, Farmer JA, Kautz JA, Gotto AM Jr. Association of levels of lipoprotein (a), plasma lipids, and other lipoproteins with coronary artery disease documented by coronary angiography. Circulation 1986;74:758-65.

19 Watts GF, Kearney EM, Taub NA, Slavin BA. Lipoprotein (a) as an independent risk factor for myocardial infarction in patients with common hypercholesterolaemia. $\mathcal{f}$ Clin Pathol 1993

20 Jenkins AJ, Steel JS, Santamaria JD, Best JD. Plasma lipoprotein (a) is increased in type 2 (non-insulin dependent) diabetic patients with microalbuminuria. Diabetologia 1992;35:1058-9.

21 Kapelrud H, Bangstad HJ, Dahl-Jorgensen K, Berg K, Hanssen KF. Serum Lp (a) concentrations in insulin dependent diabetic patients with microalbuminuria. $B M \mathcal{F}$ 1991;303:675-8.

22 Mount JM, Kearney EM, Rosseneu M, Slavin BM. Immunoturbidimetric assays for serum apolipoproteins $\mathrm{Al}$ and B using Cobas Bio centrifugal analyser. $\mathscr{f}$ Clin Pathol and B using Cobas

23 Rose GA, Blackburn H. Cardiovascular Survey Methods. WHO Monogr Ser. No 56. Geneva: WHO, 1968.

24 Petch MC. Myocardial infarction. In: Julian DG, Camm AJ, Fox KM, Hall RJC, Poole-Wilson PA, eds. Diseases of the heart. London: Baillière Tindall, 1989:1157-91.

25 World Health Organisation. Arterial Hypertension: Report of a WHO Expert Committee. World Health Organ Tech Rep Ser 1978.

26 Watts GF, Kubal C, Chinn S. Long-term variation in urinary albumin excretion in IDDM: recommendation for monitoring microalbuminuria. Diabetes Res Clin Pract 1990;9: 169-77.
27 Haffner SM, Stern MP, Gruber KK, Hazuda HP, Mitchell BD, Patterson JK. Microalbuminuria, a potential marker for increased cardiovascular risk factors in non-diabetic subjects? Arteriosclerosis 1990;10:727-31.

28 Gould MM, Mohammed-Ali V, Goubet SA, Yudkin JS Haines AP. Microalbuminuria: associations with height and sex in non-diabetic subjects. BMF 1993;306:240-2.

29 McLean JW, Tomlinson JE, Kuang W-J, Eaton DL, Chen EY, Fless GM, et al. cDNA sequence of human apolipoprotein (a) is homologous to plasminogen. Nature 1987;300:132-5.

30 Hajjar KA, Gavish D, Breslow JL, Nachman RL. Lipoprotein (a) modulation of endothelial cell surface fibrinolysis and its potential role in atherosclerosis. Natur 1989;339:303-7.

31 Rath $M$, Niendorf A, Reblin T, Dietel M, Krebber HJ, Beiseigel U. Detection and quantification of lipoprotein (a) in the arterial wall of 107 coronary bypass patients. Arteriosclerosis 1989;9:579-92.

32 Stehouwer WHL, Donker AJM, Den Ottolander GJH. Urinary albumin excretion, cardiovascular disease and endothelial bumin excretion, cardiovascular disease and endothelial
dysfunction in non-insulin-dependent diabetes mellitus. Lancet 1992;340:319-23.

33 Hutchison AS, Paterson KR. Collecting urine for microalbuminuria assay. Diabet Med 1988;5:527-32.

34 Beatty OL, Ritchie CM, Bell PM, Hadden DR, Kennedy $\mathrm{L}$, Atkinson AB. Microalbuminuria as identified by a spo morning urine specimen in non-insulin-treated diabetes: an eight-year follow-up study. Diabet Med 1995;12:261-6.

35 Labeur C Rosseneu M. Methods for the measurement of lipoprotein (a) in the clinical laboratory. Curr Opin Lipidol 1992;3:411-17. 